\title{
Pediatric immunization for the 1990s
}

$\mathrm{T}$ HE 1990S WILL BE A DECADE OF CHANGE IN IMMUNIZATION programs for children due to the availability of new vaccines and changes in recommendations for old ones. The Infectious Disease and Immunization Committee of the Canadian Paediatric Society would like to draw your attention to some of these changes.

\section{NEW HAEMOPHILUS b VACCINES FOR INFANTS}

Two new Haemophilus influenzae b $(\mathrm{HIb})$ conjugate vaccines (HIbTITER; Lederle - Praxis Biologicals and PedvaxHIB; Merck, Sharp and Dohme) were licensed in Canada in August 1991 for use in young infants. Both vaccines have been extensively tested for safety and are very effective $(1,2)$. Although immunization with both new vaccines begins at two months of age, the schedules and total number of doses differ. Please consult the statement of the National Advisory Committee on Immunization (3) or the manufacturer's package insert for details. Unlike the older $\mathrm{HIb}$ conjugate vaccine (ProHIBIT; Connaught Laboratories) which is only licensed for use in children 18 months or older, implementation of a universal immunization program with either HIbTITER or PedvaxHIB has the potential virtually to eliminate invasive $\mathrm{HIb}$ disease such as meningitis, septic arthritis and epiglottitis. Hopefully, funding will be forthcoming in all provinces and territories to cover the cost of such a program.

\section{UNIVERSAL HEPATITIS B IMMUNIZATION}

Both the Canadian Paediatric Society (4) and the National Advisory Committee on Immunization (5) have recommended that the current selective high risk hepatitis B immunization program be changed to a universal immunization program with emphasis on infants and adolescents. The current selective policy has not been successful in controlling hepatitis B infection in Canada. Much of the infection is occurring in 'nonhigh risk' individuals through heterosexual transmission. A universal program will in time control this problem. Hopefully, the cost of the vaccine will decrease so as to make the program affordable to the provinces and territories.

\section{COMBINATION VACCINES: THE INFANT PIN-CUSHION}

The difficulties in integrating the new conjugate $\mathrm{HIb}$ vaccine and the hepatitis $B$ vaccine into a convenient infant schedule are substantial. Either of the new HIb conjugate vaccines can be given simultaneously with diphtheria/pertussis/tetanus and oral polio vaccines but require separate intramuscular injection. A two injection visit requires some psychological adjustments for health care providers and parents but is well tolerated by infants. The new HIb vaccines neither add measurably to the systemic adverse effects of the diphtheria/pertussis/tetanus vaccine nor cause significant local adverse reactions. Simultaneous administration of HIb vaccines with the routine vaccines does not impair responses to any of the components.

Parents can be reassured that these multiple antigen presentations do not begin to saturate the ability of the infant's immune system to recognize and respond to each. What about the hepatitis B vaccine? A three shot visit is not acceptable to most parents making extra visits necessary until expanded combination vaccines are developed.

What is holding up the development of expanded combination vaccines? The problems are complex, so physicians - and parents - must be patient. Combination vaccines must be carefully tested to document the safety, stability and immunogenicity of each component. Since this is a costly and time consuming process, manufacturers would prefer to make a number of compositional changes at once. An immediate problem is that neither manufacturer of the recently licensed $\mathrm{HIb}$ conjugates currently markets all of the other vaccine components. Moreover, performance and stability of the HIb conjugates might be affected adversely by such mixtures. Studies of combinations of various diphtheria/pertussis/tetanus vaccines and $\mathrm{HIb}$ conjugate vaccines in infants are underway.

As for broader combinations that include hepatitis B vaccine ... don't hold your breath. Our passion for one-shot convenience represents a complex technical and political challenge that will not be easily met. 


\section{REFERENCES}

1. Black SB, Shinefield HR, Fireman B, Hiatt R, Polen M, Vittinghoff E. Efficacy in infancy of oligosaccharide conjugate Haemophilus influenzae type b $(\mathrm{HbOC})$ vaccine in a United States population of 61,080 children. The Northern California Kaiser Permanente Vaccine Study Center Pediatrics Group. Ped Infect Dis J 1991;10:97-104.

2. Santosham M, Wolff M, Reid R, et al. The efficacy in Navajo infants of a conjugate vaccine consisting of Haemophilus influenzae tybe b polysaccharide and Neisseria meningitidis outer-membrane protein complex. N Engl J Med 1991;324:1767-72.

3. National Advisory Committee on Immunization. Statement on Haemophilus influenzae type b conjugate vaccines for use in infants and children. Can Dis Weekly Rep 1991:17-39:210-3.

4. Infectious Diseases and Immunization Committee Canadian Paediatric Society. Hepatitis B in Canada: The case for universal vaccination. Can Med Assoc $\mathrm{J}$ 1992; 146:25-8.

5. National Advisory Committee on Immunization. Statement on universal immunization against hepatitis B. Can Dis Weekly Rep 1991;17-31:165-71.

\author{
NE MacDonald, MD, FRCPC \\ OHawa, Ontario \\ $R$ Gold, MD, FRCPC \\ Toronto, Ontario \\ DE Scheifele, MD \\ Vancouver, British Columbia \\ VJH Marchessault, MD, FRCPC \\ OHawa, Ontario
}




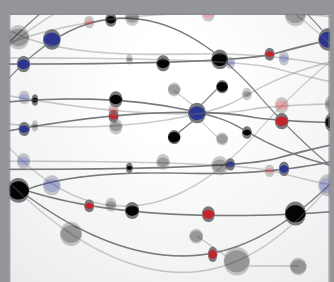

The Scientific World Journal
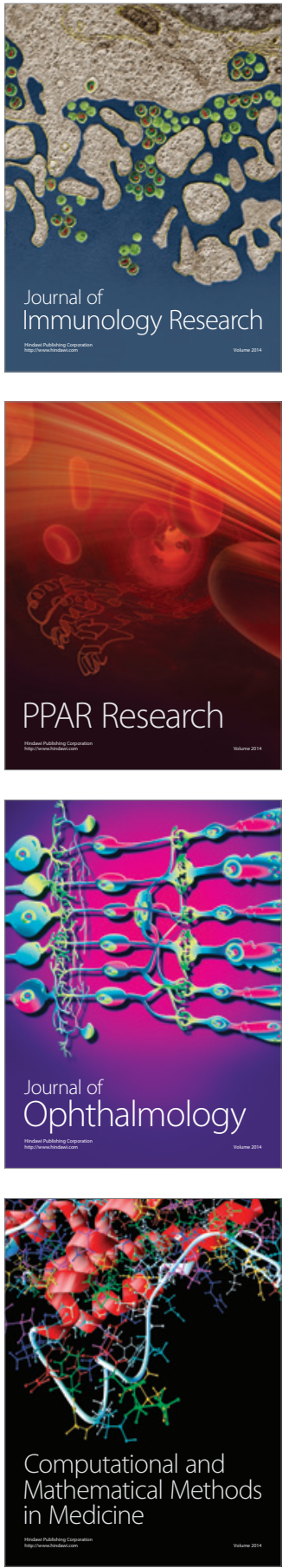

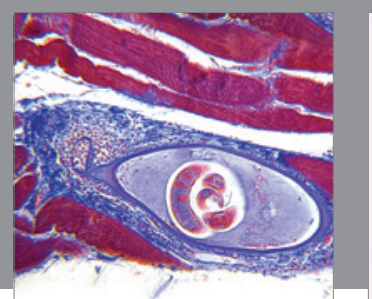

Gastroenterology Research and Practice

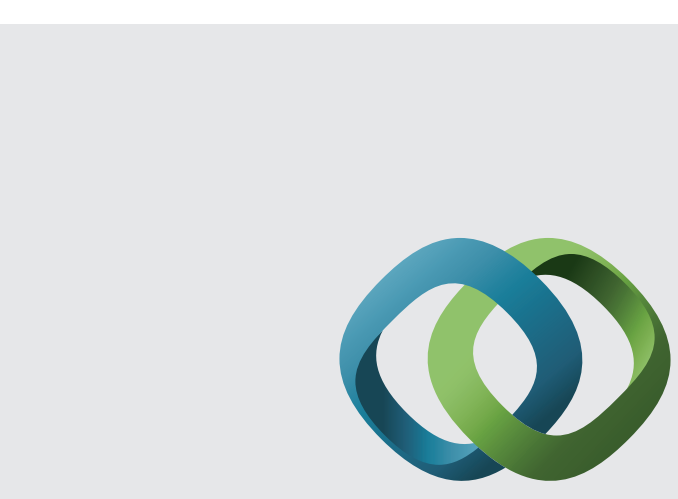

\section{Hindawi}

Submit your manuscripts at

http://www.hindawi.com
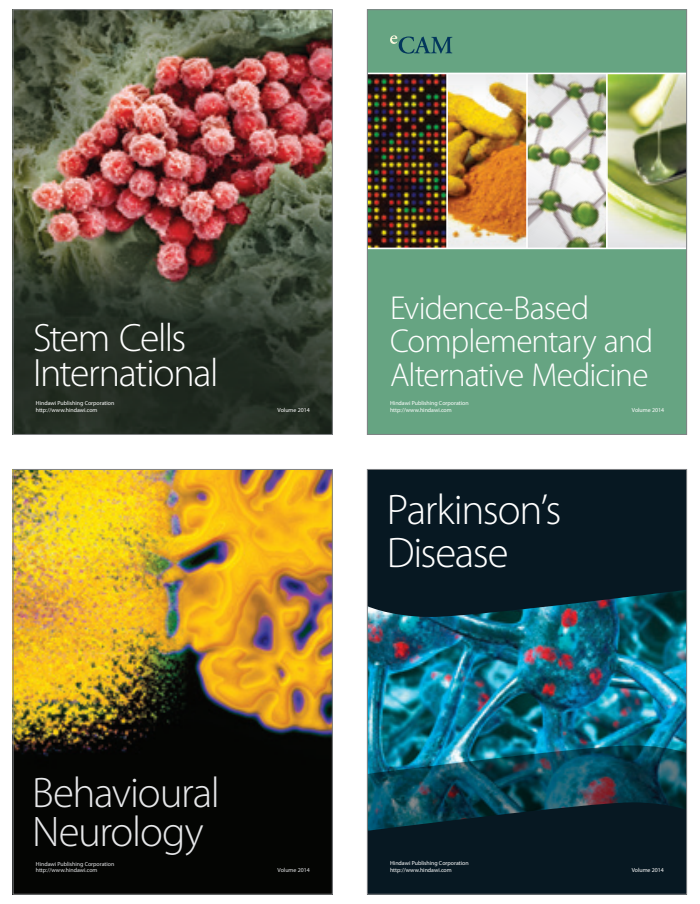
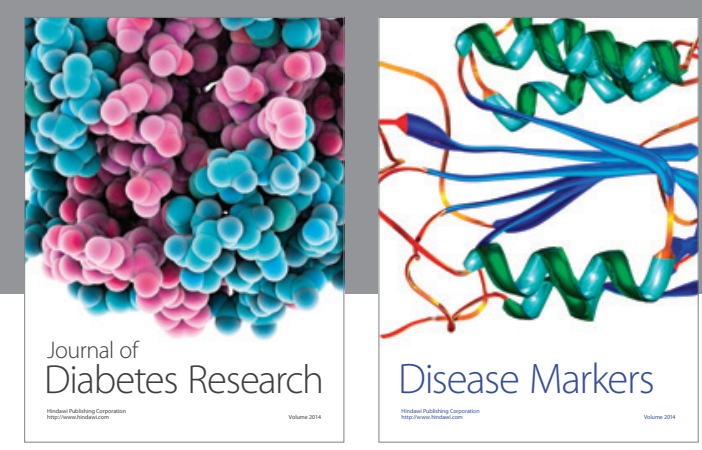

Disease Markers
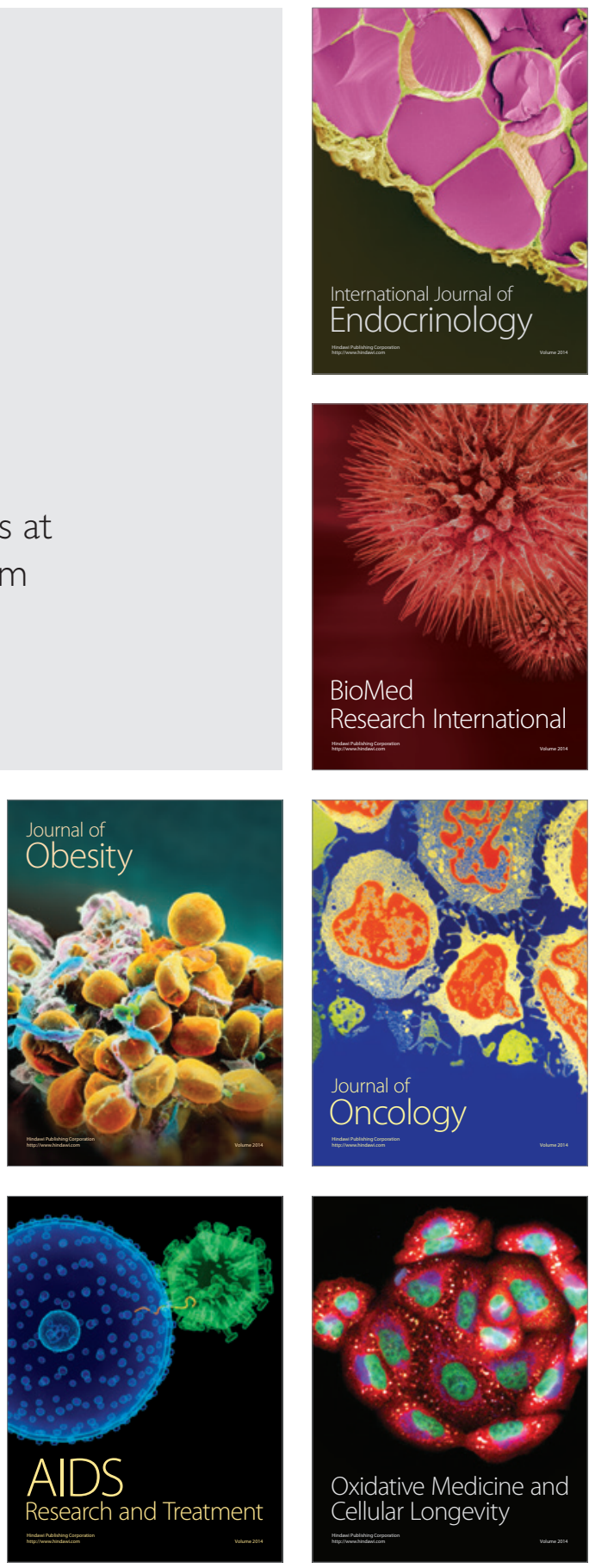